\title{
El diagnóstico de patología mamaria benigna aumenta el riesgo de futuro cáncer de mama
}

\section{Objetivo}

Estimar el riesgo de desarrollar cáncer de mama a partir de diferentes tipos de lesiones mamarias benignas potencialmente precursoras.

\section{Diseño}

Estudio de cohortes.

Lugar

Mayo Clinic College of Medicine, EE.UU.

\section{Pacientes}

Se seleccionaron 9087 pacientes entre 18-85 años de edad, quienes habían sido sometidas a biopsia mamaria, entre 19671991, cuyo resultado arrojó patología mamaria benigna.

El número de carcinomas observados se comparó con el número de casos esperados de acuerdo a los datos del registro de vigilancia epidemiológica de IOWA, ya que la población tenía similares características demográficas.

\section{Evaluación de factores pronósticos}

Se evaluó histología de la biopsia (enfermedad no proliferativa y enfermedad proliferativa con y sin atipía), la edad al momento de la biopsia, el status menopáusico y la historia familiar de cáncer de mama (uno o más familiares de primer grado con cáncer de mama diagnosticado antes de los 50 años o dos o más familiares, uno de ellos de primer grado con cáncer de mama) o débil (antecedentes de menor grado o sin antecedentes)

\section{Medición de resultados principales}

Se evaluó la asociación entre los factores pronósticos y el riesgo de desarrollar cáncer de mama ajustando* por histología, edad al diagnóstico de patología benigna y fuerza de la historia familiar.

\section{Resultados principales}

El seguimiento (media de 15 años) fue completo para el evento cáncer. El tiempo medio entre la biopsia original y el diagnóstico de cáncer mamario fue 10,7 años.

El $67 \%$ presentó lesiones no proliferativas, $30 \%$ proliferación sin atipía y $4 \%$ hiperplasia atípica. El RR de cáncer de mama para patología benigna fue 1,56 , variando según los distintos factores pronósticos (ver tabla). El riesgo no aumentó en mujeres sin historia familiar fuerte y con lesiones no proliferativas.

\begin{tabular}{|c|c|c|c|c|}
\hline Población & \begin{tabular}{|c|}
$N^{0}$ de \\
mujeres
\end{tabular} & \begin{tabular}{|c|}
$N^{\circ}$ de eventos \\
observados
\end{tabular} & $\begin{array}{c}N^{0} \text { de eventos } \\
\text { esperados }\end{array}$ & RR (95\% CI) \\
\hline Total & 9087 & 707 & 453 & $1,56(1,45-1,68)$ \\
\hline $\begin{array}{l}\text { Edad menor a } 30 \text { años al } \\
\text { diagnóstico de patología benigna }\end{array}$ & 726 & 21 & 11.5 & $1,83(1,13-2,80)$ \\
\hline Enfermedad no proliferativa & 6061 & 379 & 297.7 & $1,27(1,15-1,41)$ \\
\hline $\begin{array}{l}\text { Enfermedad proliferativa con } \\
\text { ati pía }\end{array}$ & 344 & 64 & 15.1 & $4,24(3,26-5,24)$ \\
\hline $\begin{array}{l}\text { Historia familiar de cáncer de } \\
\text { mama fuerte }\end{array}$ & 966 & 110 & 57 & $1,93(1,58-2,32)$ \\
\hline
\end{tabular}

\section{Conclusiones}

El antecedente de patología mamaria benigna debe ser tenido en cuenta como un factor de riesgo para cáncer de mama, especialmente las lesiones proliferativas con y sin atipía. Una fuerte historia familiar fuerte sería un factor predictor independiente.

Fuentes de financiamiento: National Institute of Health; Brest Cancer Foundation y Andersen Fundation

\section{Comentario}

El estudio utilizó una población seleccionada con patología benigna y comparó el riesgo de cáncer de mama en estas pacientes en relación con el riesgo esperado para una población similar. Los resultados permitieron observar un asociación inversa entre el riesgo de desarrollar cáncer de mama y la edad al momento de la biopsia, además se demostró el importante papel que tiene la anatomía patológica, especialmente en presencia de enfermedad proliferativa con atipía, así como la historia familiar, que fue un factor de riesgo independiente.

El reciente estudio NSABP también halló una asociación significativa entre cáncer mamario y patología benigna, incluyendo la no proliferativa'.

En el presente estudio, de prolongado y completo seguimiento, se destaca el hallazgo de que las mujeres con lesión no proliferativa y sin fuerte historia familiar de cáncer de mama no tenían aumento de riesgo para desarrollar cáncer en el futuro.

El impacto que este estudio tiene para nuestra práctica es poder informar a nuestras pacientes sobre el riesgo potencial de desarro- llar un cáncer de mama; y en los casos de enfermedades no proliferativas $(52 \%$ en esta cohorte y una proporción similar en el estudio de Dupont y $\mathrm{Page}^{2}$ ) tranquilizar a las pacientes, sobre todo si no presentan antecedentes o aún con antecedentes familiares débiles. También nos permitirá informar con más precisión a aquellas pacientes con enfermedades proliferativas, la magnitud del riesgo que presentan para el desarrollo de un futuro cáncer de mama, y ofrecerles supervisión clínica estrecha y mediante procedimientos de imágenes convencionales o experimentales.

\section{Conclusiones del comentador}

Conocer el riesgo que presentan nuestras pacientes con patología de mama benigna nos permitirá informar mejor a nuestras pacientes, e indicar el seguimiento necesario en cada caso, así como evaluar la necesidad de profilaxis primaria.

Andrea Cohen [ Servicio de Ginecología y Obstetricia. Hospital General de Agudos Cosme Argerich. ]

Cohen AF. El diagnóstico de patología mamaria benigna aumenta el riesgo de futuro cáncer de mama. Evid actual pract ambul 2005;8:138. Comentado de: Hartmann LC, Sellers TA., Frost MH, Lingle WL, Degnim A.C, et al. Benign Breast Disease and the Risk of Breast Cancer. N Engl J Med 2005; 353:229237. PMID: 16034008 [PubMed - indexed for MEDLINE]

\section{Referencias}

1. Wang J, Costantino JP, Tan-Chiu E, Wickerham DL, Paik S, Wolmark N. Lower-category benign breast disease and the risk of invasive breast cancer. J Natl Cancer Inst 2004;96:616620.

2. Dupont WD, Page DL. Risk factors for breast cancer in women with proliferative breast disease. N Engl J Med 1985;312:146-151. 